\title{
Evaluation and Comparison of Sulfate Anions Removal from Artificial and Industrial Wastewaters by Nanofiltration Process in a Laboratory Scale
}

\author{
Ali Hangi ${ }^{1}$, Ali Mohebbi ${ }^{1{ }^{*},}$, Mohammad Mirzaei ${ }^{2}$ and Hossein Kaydani ${ }^{1}$ \\ ${ }^{1}$ Department of Chemical Engineering, Faculty of Engineering, Shahid Bahonar University of Kerman, \\ Kerman, Iran \\ ${ }^{2}$ Department of Chemistry, Shahid Bahonar University of Kerman, Kerman, Iran
}

\begin{abstract}
In this study, the performance of a nanofiltration process in sulfate anion reduction from artificial and industrial wastewaters was investigated. For this purpose, the effects of pressure, temperature, and volume flow rate and sulfate concentration of feed were studied. In order to prepare artificial wastewater (i.e. Sodium Sulfate) and to adjust the $\mathrm{pH}$ of the feed, both Sodium Hydroxide and Acetic Acid were used. The concentration of sulfate in the artificial wastewater was in the range of the industrial one (i.e. 400 500 ppm) and the pressure range, which had the most important influence on retention, was between $138 \sim 552 \mathrm{kPa}$. In order to organize the experiments and obtain a specific procedure to perform the required tests, Minintab 16 software has been utilizes. The results showed that the reduction of sulfate anions, which had bivalent charge with big molecule size, occurred at high level of 96 99\%. Higher pressure and temperature led to increase in this retention rate, while it reduced at high level of sulfate concentration in the feed. The condition in which the pressure, temperature, and feed flow rate were respectively $50345 \mathrm{kPa}, 25^{\circ} \mathrm{C}$ and $4 \mathrm{~L} / \mathrm{min}$ were indicated as the optimum condition.
\end{abstract}

Keywords: Sulfate anion, Industrial wastewater, Nanofiltration, Removal.

\section{INTRODUCTION}

In last few decades, oil was regarded as the most important wealth of countries, however, it is highly expected that in near future, water will be exchanged with oil, since there are numerous alternative sources of energy such as gas, nuclear energy, solar energy and so forth. But when it comes to water, there is only one option which is just water. Hence, a great deal of time and effort has been invested to economize water resources using different methods among which wastewater treatment has attracted the attention of many researchers in recent years. Two third of the Earth is overlaid by water and almost all substances are soluble in water, the solubility of which appertains to different parameters such as temperature, pressure, $\mathrm{pH}$, chemical potential and partial concentration of other substances. These impurities are categorized as suspended solids, gases, and dissolved solids [1].

In recent years, strict limitations have been placed on industrial wastewaters. However, in such restrictions, not much attention has been paid to the issues related to dissolved sulfate [2]. The damage caused by sulfate emissions is not direct, since sulfate is a chemically inert, non-volatile, and non-toxic

*Address correspondence to this author at the Department of Chemical Engineering, Faculty of Engineering, Shahid Bahonar University of Kerman, Kerman, Iran; Tel/Fax: +98 343211 8298; E-mail: amohebbi@uk.ac.ir, amohebbi2002@yahoo.com compound. Sulfate anions are discharged into the aquatic environment in wastes from industries which use sulfates and sulfuric acid, such as mining and smelting operations, kraft pulp and so forth. High sulfate concentrations as well as low $\mathrm{pH}$ conditions can cause various environmental and health related problems. The cations accompanied by sulfate are categorized into two types; soluble like $\mathrm{Na}^{+}, \mathrm{K}^{+}, \mathrm{Mg}^{2+}$, and insoluble like $\mathrm{Ca}^{2+}, \mathrm{Ba}^{2+}[3]$.

Sulfate is one of the least toxic anions with a lethal dosage for human of $45 \mathrm{~g}$ as potassium or zinc salt; in such case, it is questionable as to whether toxicity is associated with the sulfate or the counter ions. The reported minimum dosage of magnesium sulfate in mammals is $200 \mathrm{mg} / \mathrm{kg}$. People consuming drinking water containing sulfate in concentrations exceeding $600 \mathrm{mg} / \mathrm{L}$ commonly experience cathartic effects; resulting in purgation of the alimentary canal [4].

High concentration of this anion in industrial waters and wastewaters can lead to several problems as follows; scaling production in heat exchangers and boilers is resulted in by sulfate. At low pH conditions, sulfates absorb protons, which cause corrosion on transmission systems. Such problem could be overcome by adding $\mathrm{Ca}(\mathrm{OH})_{2}$, which increases $\mathrm{pH}$. However, despite $\mathrm{pH}$ increasing, the wastewater will be saturated by $\mathrm{CaSO}_{4}$ and high concentrations of $\mathrm{CaSO}_{4}$ in water reduce production and damages equipment [5]. In sum, sulfates removal from effluents is essential 
for; a) prevention of salination of surface water, b) prevention of scaling, c) prevention of bio-corrosion, d) prevention of acid corrosion [4].

There are various processes for treatment of sulfate laden waters including chemical treatment, semipermeable membranes, ion-exchange, biological mechanisms and so forth. Chemical treatment processes with mineral precipitation are generally the least expensive but produce the largest amounts of waste. Biological sulfate reduction has an additional advantage of removing trace metals from the mine water. For the removal of sulfate from mine water, the lime/limestone process, GYP-CIX as an ion-exchange process, and biological sulfate reduction in a bioreactor are the most suitable processes [4].

In the past, sulfate was removed by Barium Carbonate. Kun [6] studied the removal of sulfate with Barium Carbonate and despite obtaining good results, he identified three problems: 1) a long retention time requirement, 2) high concentration of soluble Barium in the treated water when more Barium Carbonate was dosed than stoichiometrically required, 3) and the last one was the high cost of the Barium Carbonate. Volman [6] overcame the cost problem by demonstrating that Barium Sulfate could be recovered and reduced efficiently and economically with coal under thermal conditions to produce Barium Sulfide. Wilsenach [6] demonstrated the economic viability by calculating the cost of producing Barium Sulfide from Barium Sulfate. Trusler et al. [6] developed a barium carbonate method using a two-stage fluidized bed reactor system to overcome the long retention time and the high barium concentration in the treated water.

Košutić et al. [7] surveyed the removal of sulfate and other inorganic compound from drinking waters by nanofiltration experiments in Prud (Croatia). Their results have shown very high retentions of sulfates (more than 97\%).

International Network for Acid Prevention (INAP) institute [4] studied sulfate removal from industrial wastewaters. They selected several processes to reach this purpose. Table 1 summarizes the results of this study. The selection criteria for each process were based on: (1) applicability to sulfate removal, and (2) availability of data on sulfate removal and costs. All the experiments have been performed for mine water of Sceunda coal mine near Johannesburg in South Africa. The mine water was characterized by high TDS $(4 \mathrm{~g} / \mathrm{L})$ and sulfate $(2.2 \mathrm{~g} / \mathrm{L})$ concentrations and $\mathrm{pH}=8.4$. Tubular Reverse Osmosis (TRO) pilot plant was investigated by them. Over the test period of $1800 \mathrm{hrs}$, the average salt rejection was $96 \%$. A decrease in standard flux of $5 \%$ or an increase of $10 \%$ in operating pressure was a sign that the membranes needed to be cleaned. It was reported that after every $350 \mathrm{hrs}$ of operation, the membranes should be cleaned, to restore the flux.

Aleixandre et al. [8] carried out an evaluation of sulfate concentrations in the different residual streams of a tannery. Tannery industries generate wastewater containing high concentrations of sulfates. In the pickling process, the presence of sulfates is due to the Sulfuric acid added for $\mathrm{pH}$ lowering, and Chromium is used as $\mathrm{Cr}_{2}\left(\mathrm{SO}_{4}\right)$ in the tanning process. Concentrations higher than $2000 \mathrm{mg} / \mathrm{L}$ were usual in tannery wastewater, and the legal standard was 1000 $\mathrm{mg} / \mathrm{L}$ at the beginning of 2005 in Catalonia (Spain). Sulfate reduction of more than $90 \%$ was achieved, and also permeate quality was reported to be good enough to be reused.

Benatti et al. [9] investigated Barium and Calcium precipitation of sulfate from mixed waste chemicals and the effect of the wastewater composition on the sulfate precipitation. The results showed that at the concentration of $80 \mathrm{~g} / \mathrm{L}$, Barium precipitation achieved a sulfate removal up to $61.4 \%$ while Calcium precipitation provided over $99 \%$ sulfate removal. The precipitate characterization showed chemical compositions with no toxic risks that favored its reuse in innumerous processes applications.

Tait et al. [10] studied sulfate removal by crystallization. Batch experiments on a landfill

Table 1: INAP's Sulfate Reduction Methods [4]

\begin{tabular}{|c|c|c|c|}
\hline Proposed methods & Feed Concentration (ppm) & Product Concentration (ppm) & 1219 \\
\hline \hline Mineral Precipitation & 3000 & 69 & 59.37 \\
\hline lon-exchange & 649 & 113 & 99.73 \\
\hline Reverse Osmosis & 1149 & 198 & 90.16 \\
\hline Biological treatment & 8342 & 97.63 \\
\hline
\end{tabular}


wastewater with a similar composition to other sulfate rich industrial wastewaters (high levels of organic and inorganic contaminants) were used. The results showed that Gypsum crystallization was an effective means for bulk removal of sulfate from highly contaminated wastewaters, but precipitation processes, therefore, could not economically reduce sulfate to very low levels. At an industrial scale, it was more economical to operate with crystal recycle than with manufactured seed only. Unfortunately, impurities in the wastewater substantially increased the solubility of gypsum and a substantial excess of calcium might be necessary to attain the desired level of sulfate removal.

Haghsheno et al. [11] studied sulfate removal from the Sarcheshmeh Copper Complex (Kerman province, Southeast of Iran) wastewater, by an anion exchange resin. Batch experiments of sulfate anions adsorption on Lewatit k6362 resin were carried out. The results of their study showed that maximum removal of sulfate anions takes place in the resin dosage of $1000 \mathrm{mg} / 100$ $\mathrm{ml}$, and with increasing the feed flow rate from 30 to 70 $\mathrm{ml} / \mathrm{min}$, the anionic content in the outlet stream of the column increased. In addition, other ions in the effluent caused much inconvenience and had adverse effects on system performance [2, 11]. Alizadeh et al. [12] researched sulfate removal from ABS plant wastewater by anaerobic biological treatment. The maximum sulfate removal percentage was $86 \%$ in an experimental setup. Possibility of using wastewater with no pre-treatment and no change in temperature was the advantages of this method. However, high corrosion characteristic of the microorganism, which was used in their study, was the major disadvantage. Although there are some studies on removal of sulfate anion form wastewaters, application of new technologies such as nanofiltration seems to be necessary, particularly for elimination of pollutants from industrial wastewaters.

In this study, sulfate removal by a nanofiltration process in a laboratory scale was carried out. To achieve this purpose, the effects of different independent parameters (i.e. pressure, temperature, volume flow rate and sulfate concentration of feed) on sulfate removal and permeate flux were investigated using artificial wastewater. Then optimum conditions of sulfate removal were obtained. To investigate the effects of other ions, which are present in industrial wastewater, on sulfate elimination and permeate flux, all tests, especially at optimum conditions, were repeated for the industrial wastewater.

\section{NANOFILTRATION PROCESS}

Nanofiltration is a kind of membrane processes, which is considered as a physical treatment (i.e. without occurrence of any chemical reaction) with pressure as the driving force. Membrane processes are categorized according to the smallest particles which pass the membrane; microfiltration (MF), ultrafiltration (UF), nanofiltration (NF) and reverse osmosis (RO). Based on the size of particles passing the membrane and the operating pressure, NF is placed between UF and RO. These membranes also have selective separation of molecules and ions with high molecular weight. For instance, Sulfate $\left(\mathrm{SO}_{4}^{2-}\right)$, a bivalent anion with high molecular weight cannot pass whereas chloride anions $\left(\mathrm{Cl}^{-}\right)$can pass [13].

Saving energy during separation process due to no change in phase and temperature between feed and product, being faster due to low thickness of membranes, which leads to fast mass transfer, being more efficient and less usage of solvents or chemical aids than other separation processes, no peril to environment, high flexibility in plant design and possibility of being combined with other separation processes, and simple technology can be mentioned as some advantages of membrane, which are used in different industries [14, 15].

\subsection{Characteristics of Membrane Filtration}

\subsubsection{Permeability Coefficient}

Permeability coefficient is the flux permeate stream on the unit pressure, which is defined as below:

$L_{p}=\frac{J}{P_{e}}$

where $L_{p}$ is membrane permeability coefficient, $P_{e}$ is effective pressure on the membrane, and $J$ is permeate flux [15].

The relation between permeate of solute and operating pressure for pure solute is linear. According to Darcy's law, filtration flux depends on operating conditions, membrane characteristics and the fluid under filtration, i.e:

$J=L_{p} \frac{\Delta P}{\mu}$

where $J$ is permeate flux, $\Delta P$ represents pressure difference along membrane or effective pressure on the membrane, and $\mu$ is solute dynamic viscosity [15]. 
If membrane permeability is considered as the initial hydraulic resistance of membrane, it will be shown as below:

$J=\frac{\Delta P}{\mu \cdot R_{M}}$

where $R_{M}$ is membrane initial hydraulic resistance expressed in terms of meter [15].

\subsubsection{Retention}

Retention $(R)$ is a function of membrane's selectivity properties. It is calculated by the equation below:

$$
R=1-\frac{C_{p}}{C_{a}}
$$

where $C_{p}$ is the concentration of specific element in filtrate (permeate), and $C_{a}$ is the concentration of the element in feed [15].

Due to concentration polarization phenomenon, two retention terms as Intrinsic Retention and Observed Retention are used. Concentration polarization phenomenon is the accumulation of retained particles near the membrane surface, which causes the concentration difference between the feed solution (behind the membrane) and retained solution. Model of film theory is used to describe this phenomenon [15].

\section{MATERIALS AND METHODS}

\subsection{Experimental Setup}

Figure 1 shows the process flow diagram for the experimental setup used in this study in order to investigate the nanofiltration process efficiency. According to this figure, this setup is fully returned. It means that both permeate and concentrate outlets are turned back to the feed tank in order to avoid wasting the feed. Due to the nanofiltration mechanism, which is a type of physical removal processes, turning back the outlets is possible and has no significant effect on the results.

According to the process, which is fully returned, and due to the high pressure pump, the feed temperature raised almost $3^{\circ} \mathrm{C}$ during each experiment which took at least 30 minutes. In order to prevent this temperature increment, a cooling system similar a typical refrigerator system, was used. An electric heater was also used to adjust and control the feed temperature to assess the effect of temperature in the experiments. These cooling and heating systems shown as E-101 in Figure 1 were placed in the feed tank. As can be seen, there is a temperature control system (TIC) which indicates the feed temperature, compares it to the set point value and then signals to the heater/cooler in order to adjust the feed temperature.

F-101 refers to a microfiltration stage which is needed for bigger particles removal to protect nanofilter from fouling. It has two inner stages, 10 and 5 micron filters, which represents the pores size of the filters.

\subsection{Characteristics of Nanofiltration Module}

NF33-1812-50 was the trade mark of NF module, a spiral-wound module, with $1.84 .6 \mathrm{~cm}$. diameter, 30.5 $\mathrm{cm}$. height, and capacity of $189 \mathrm{~L} /$ day made by ASPRINN MEMBRANE, with FilmTec membranes. The

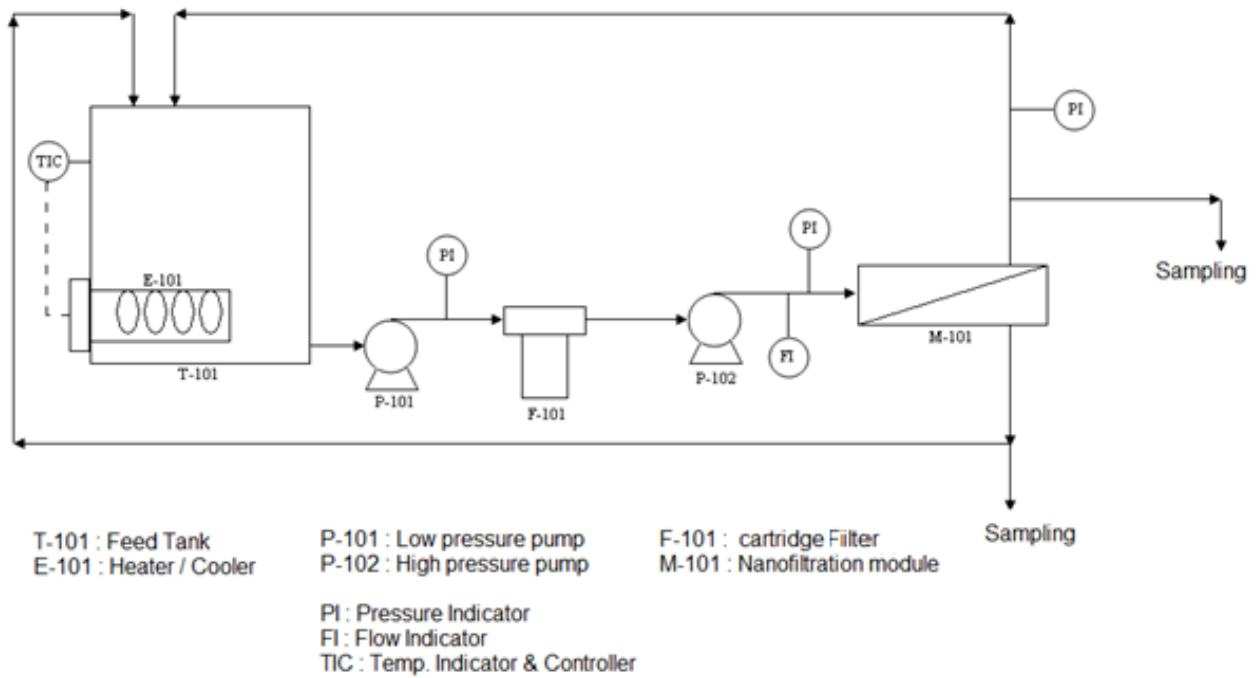

Figure 1: Laboratory setup flow diagram. 
Table 2: Characteristics of NF33-1812-50 [16]

\begin{tabular}{|c|c|}
\hline Membrane Type & Polyamide Thin-Film Composite \\
\hline \hline Maximum Operating Temperature & $113^{\circ} \mathrm{F}\left(45^{\circ} \mathrm{C}\right)$ \\
\hline Maximum Operating Pressure & $600 \mathrm{psi}(41 \mathrm{bar})$ \\
\hline $\mathrm{pH}$ Range, Continuous Operation & $2-11$ \\
\hline Active area $\left(\mathrm{m}^{2}\right)$ & 0.4255 \\
\hline
\end{tabular}

main characteristics of this module are given in Table 2. It was an asymmetric membrane with pore size gradient, an increasing in porosity from top to the bottom. Figure 2 shows the general scheme of the layers in this type of membrane. The separation characteristics of asymmetric membrane refer to the thin and compact layer, which is called selective layer [16].

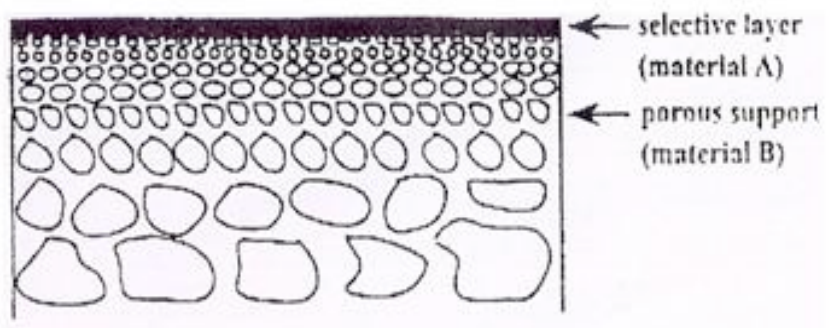

a

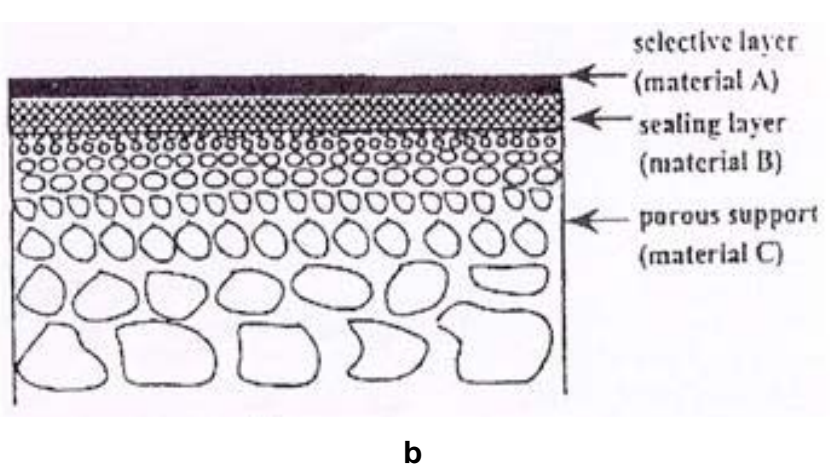

Figure 2: Thin-Film composite membranes structure, a) single layer and b) multi-layer [15].

\subsection{Sulfate Solutions}

Stock solutions were prepared from several points of wastewater stream of Tehran Oil Refining Company. Sulfate ion concentration was found in the range of 400-500 ppm. The $\mathrm{pH}$ of these samples was approximately 7 . Therefore, in all experiments the $\mathrm{pH}$ conditions were kept constant at 7 . Metrohm $654 \mathrm{pH}$ meter was used to measure the $\mathrm{pH}$ of the solution.

To measure sulfate anion concentration, ASTM D516-90 method, based on white precipitation of Barium Sulfate salt, was used. The spectrophotometer in this method was CamSpec, M350 Double Beam UVVisible Spectrophotometer at $420 \mathrm{~nm}$ wavelength. A calibration curve based on $\mathrm{SO}_{4}^{2-}$ concentration (ppm) for standard solutions with known sulfate concentration versus adsorption was needed (see Figure 3) [17].

The procedure of performing experiments at different conditions was designed by Minitab 16. Each experiment was performed at least twice at the same condition to ensure data repeatability. The precision of the measurements was mostly within $4 \%$. First, all experiments were done with the artificial wastewater, then to investigate the effect of the presence of other ions on the sulfate removal, industrial wastewater from Tehran Oil Refining Company was used. In this study $C_{p}$, which is the sulfate concentration in permeate stream, and volume flow rate of permeate were measured.

\section{RESULTS AND DISCUSSION}

\subsection{Effect of Pressure on the Sulfate Removal Rate}

Figure 4 illustrates the effect of pressure on sulfate removal from the artificial wastewater for two feed inlet concentrations of 400 and $500 \mathrm{ppm}$. In this figure, each line was obtained for a constant temperature and feed volumetric flow rate. It was observed that increase in pressure from 138 to $552 \mathrm{kPa}$, leads to increase in sulfate retention the rate of which is higher at lower pressures. According to the Spencer's study [18], increase in pressure leads to higher concentration polarization and consequently, higher sulfate retention. But there are some differences between our study and Spencer's work. First, the range of sulfate concentration of feed in that work was much higher and the trend of the variation of flux versus pressure was not linear, while linear trend (see Figure 6) can be seen in this study. Hence, in this research, the concentration polarization phenomenon is negligible [18, 19], and it cannot be an appropriate explanation of retention's accretion. In order to clarify such increment, it can be mentioned that $\mathrm{Na}^{+}$cations which are present in both artificial and industrial wastewater have very small ionic 


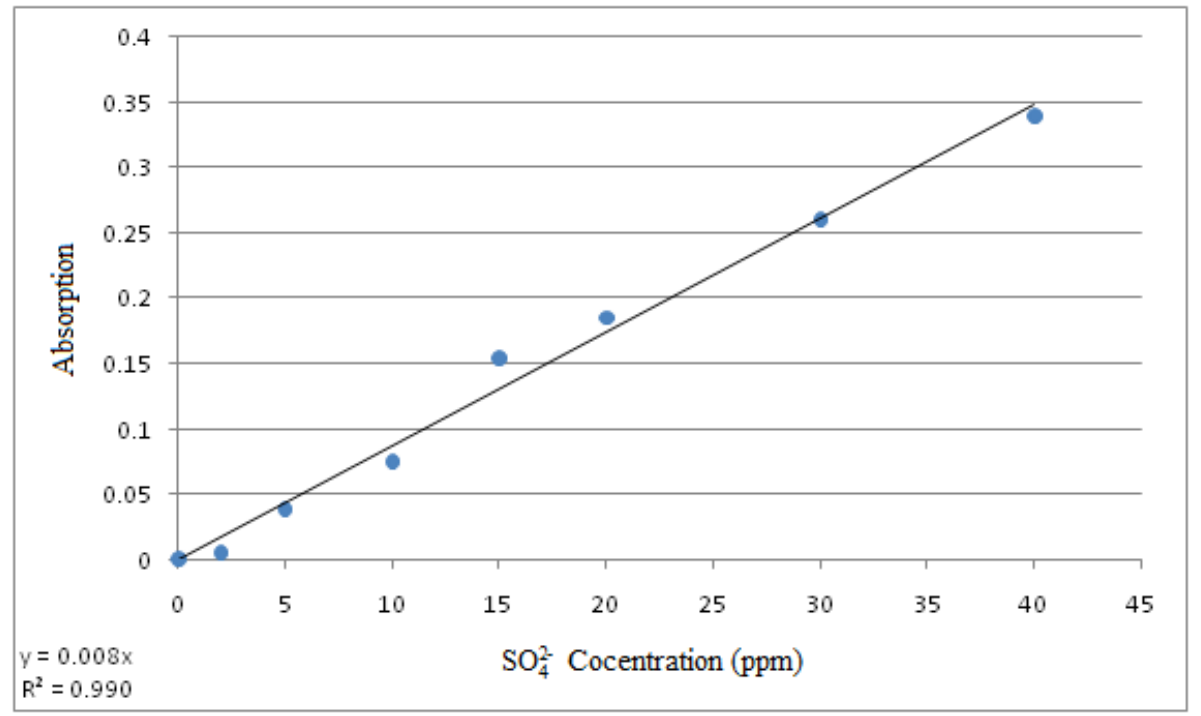

Figure 3: Calibration curve of sulfate concentration.

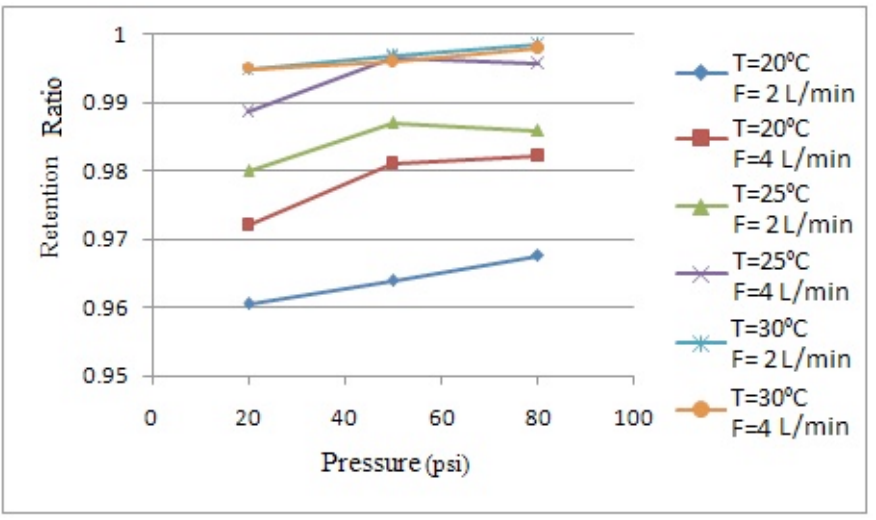

a

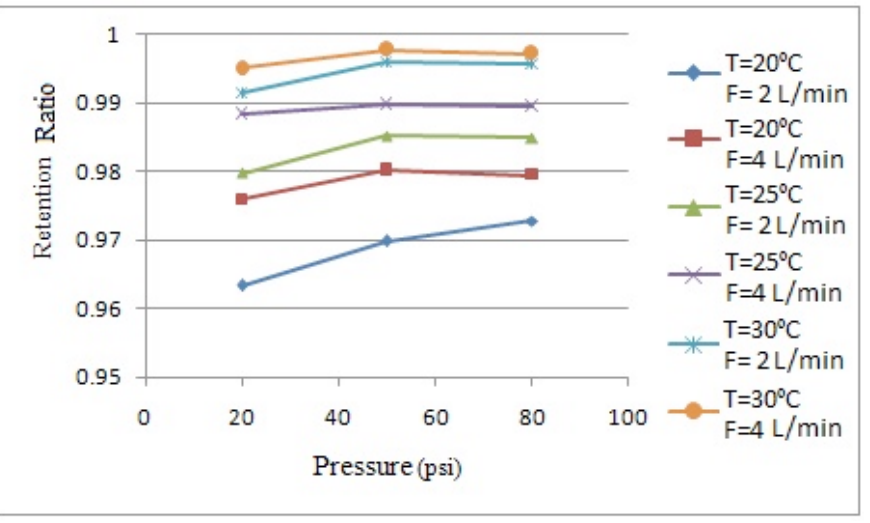

b

Figure 4: Effect of pressure on sulfate retention (Artificial wastewater); a) Feed concentration; 400 ppm, b) Feed concentration; 500 ppm.

radii and low hydration energy $(405 \mathrm{~kJ} / \mathrm{mol})$, and hence, they can enter the membrane pores, some of which remain in those pores leading to membrane surface resistance against the sulfate permeation [19].

Figure 5 shows the effect of pressure on sulfate removal from the industrial wastewater which contained $437.56 \mathrm{ppm}$ of sulfate anion. Comparison between Figures $\mathbf{4}$ and $\mathbf{5}$ illustrates that sulfate retention for this case is lower than that for the artificial wastewater. This reduction is due to the existence of cations such as $\mathrm{Ca}^{2+}$ and $\mathrm{Mg}^{2+}$ in the industrial wastewater, which neutralizes negative sites on NF membrane surface and consequently, leads to higher permeation of sulfate.

NF membrane used in this study had negative surface charge which contributes $\mathrm{SO}_{4}^{2-}$ ions repelling.
The resistance of the membrane against the fluid flow was constant, such that there were no significant differences in passing $\mathrm{Na}^{+}$and $\mathrm{SO}_{4}^{2-}$ by increasing the pressure. However, as pressure was increased above a certain value (e.g. about $335 \mathrm{kPa}$ ), flux of solution detached the cations $\left(\mathrm{Na}^{+}\right)$, and hence, it would be possible for sulfate anions to pass through the NF membrane. However, in this study, this phenomenon is not sensible due to the high sulfate anions' size.

Figure 7 shows the effect of pressure on permeate flux for the industrial wastewater. From this figure, one can see that the permeate flux decreases in comparison with Figure 6 (i.e. artificial wastewater). It is caused by impurities and bigger-than-nano particles, which are present in the industrial wastewater. These contributions lead to increase in the membrane surface resistance against the passing stream and consequently, results in decrease in flux. Each line in 


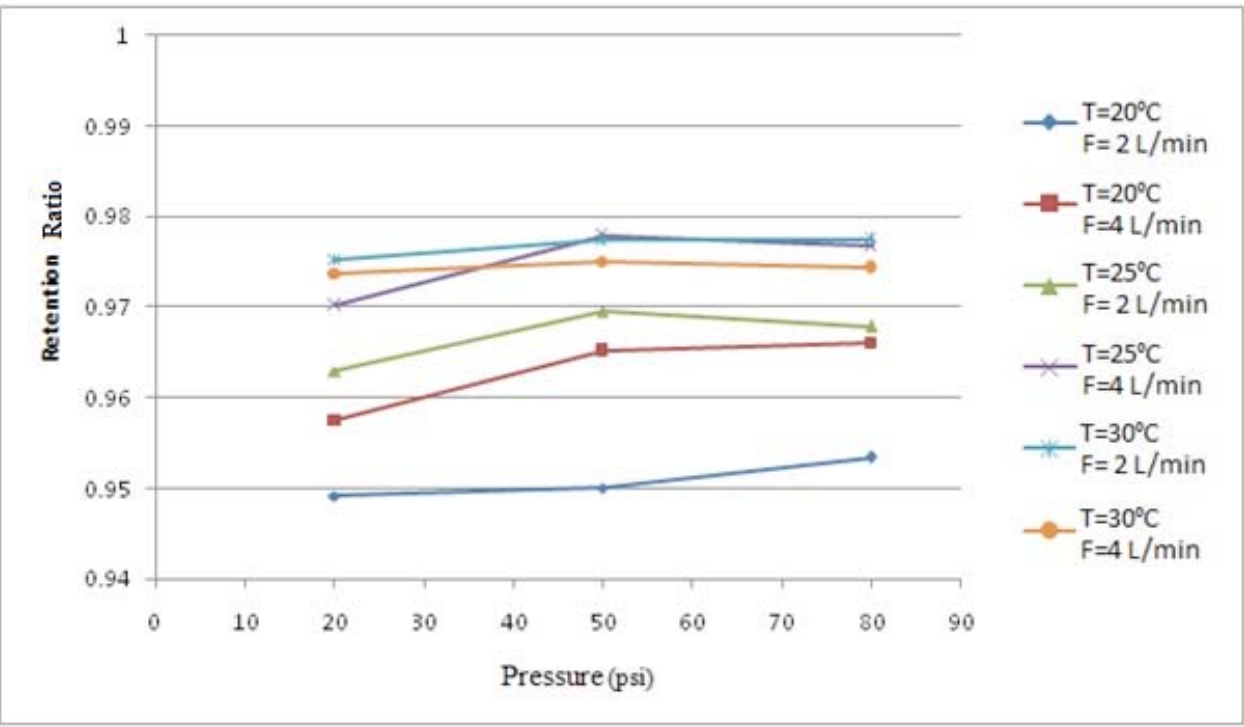

Figure 5: Effect of pressure on sulfate retention (Industrial wastewater).

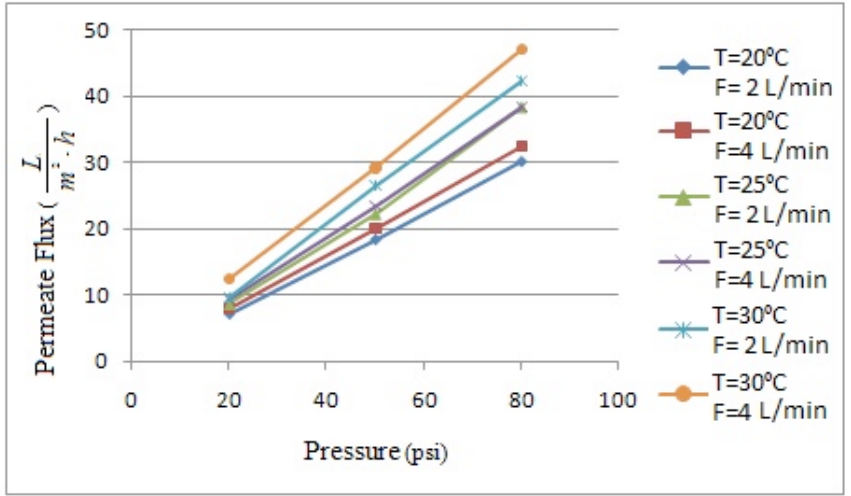

a

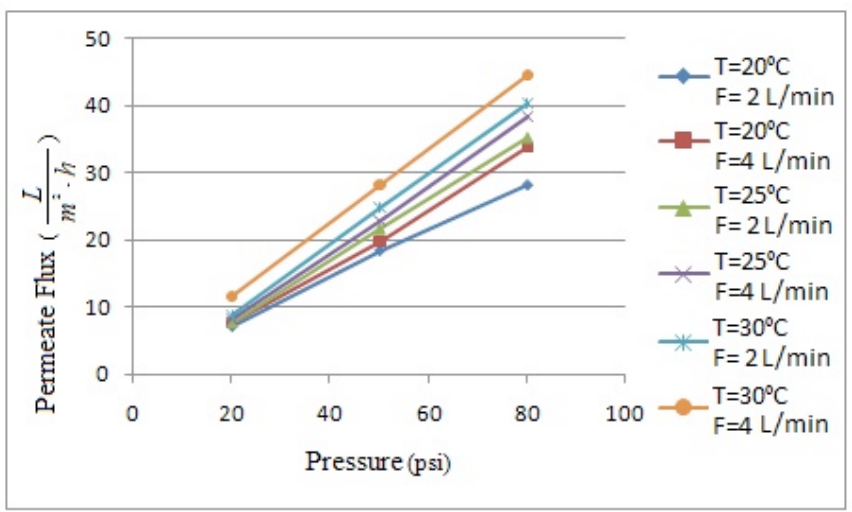

b

Figure 6: Effect of pressure on permeate flux (Artificial wastewater); a) Feed concentration; 400 ppm, b) Feed concentration; 500 ppm.

Figure $\mathbf{6}$ is related to the conditions of constant feed temperature and volume flow rate, and each sub-figure is related to a constant concentration.

\subsection{Effect of Temperature on Sulfate Removal}

The results of sulfate retention from the artificial wastewater, for different feed temperatures and two feed concentrations are shown in Figure 8. In this figure, each line was obtained at constant pressure and feed volumetric flow rate and each sub-figure is only for a constant concentration. As one can see, increase in temperature from 20 to $30{ }^{\circ} \mathrm{C}$ results in an increase in the retention due to higher solubility of salt $\left(\mathrm{Na}_{2} \mathrm{SO}_{4}\right)$, lower probability of concentration polarization and preservation of membrane surface characteristic. According to these results, the temperature should be lower than the membranes endurance limitation to protect the performance of membrane. Figure 9 shows the effect of temperature on sulfate retention for the industrial wastewater. Comparing Figures $\mathbf{9}$ and 8, one can see that the sulfate retention for the industrial wastewater is lower than that for the artificial wastewater. This behavior is similar to the effect of pressure on sulfate retention.

Figure 10 shows the effect of temperature on permeate flux for the artificial wastewater. This figure illustrates that the relation between permeate flux and temperature is almost linear. The reasons for the small observed deviation from linear trend are due to reduction of feed kinematic viscosity, osmotic pressure and increase in solution diffusion at higher temperature. Moreover, the results for the industrial wastewater are shown in Figure 11. 


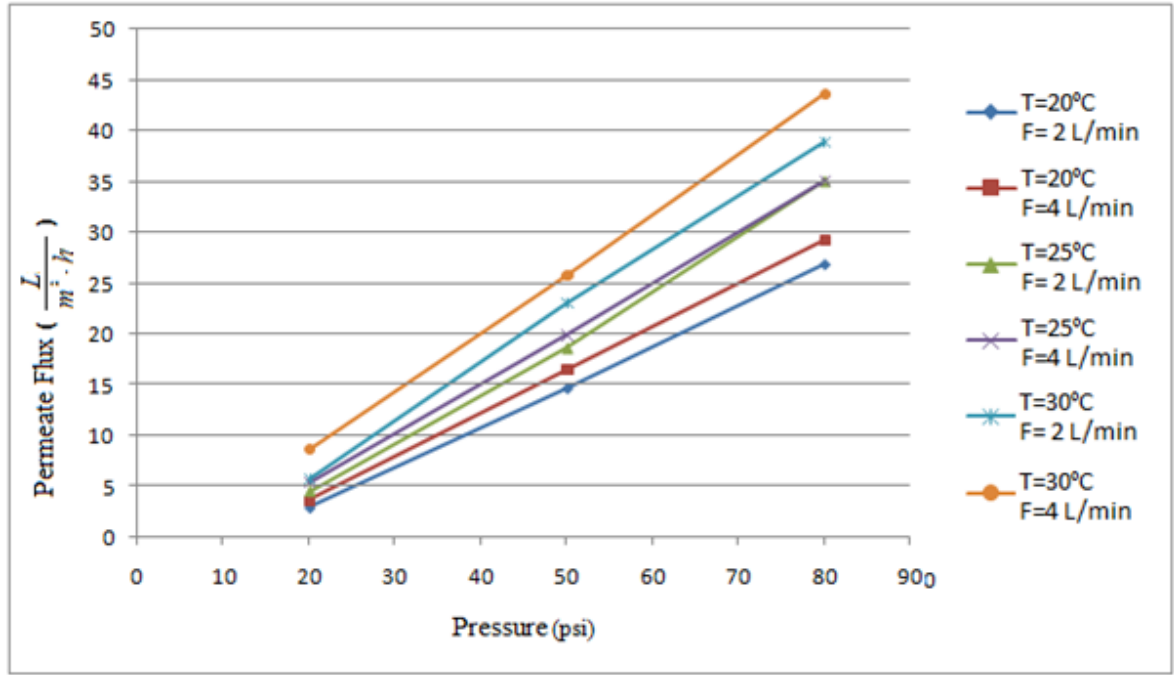

Figure 7: Effect of pressure on permeate flux (Industrial wastewater).

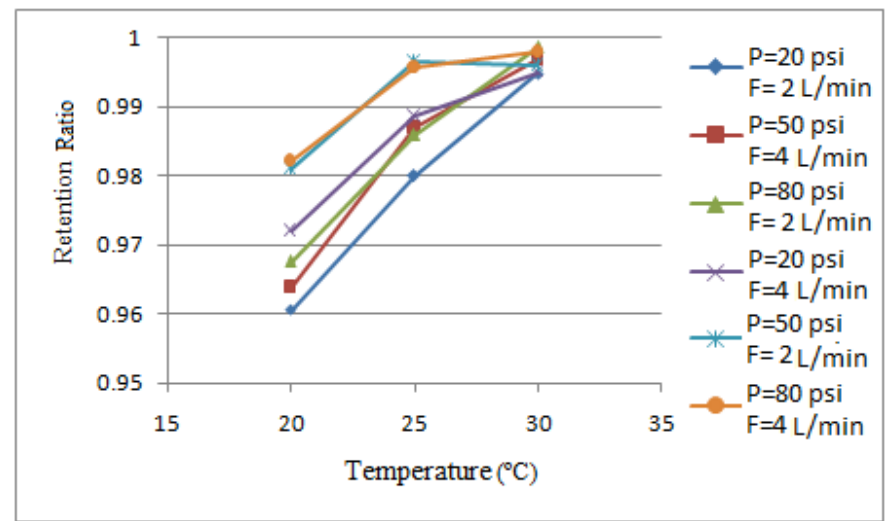

a

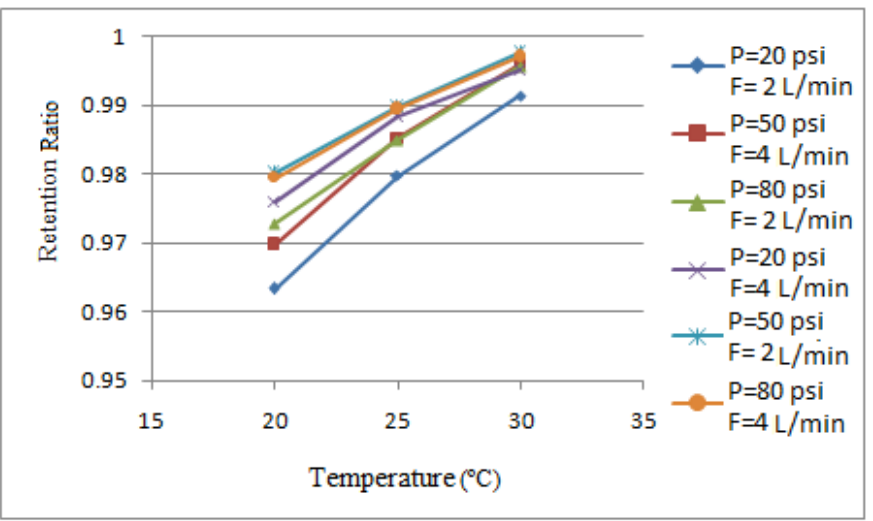

b

Figure 8: Effect of temperature on sulfate retention (Artificial wastewater); a) Feed concentration; 400 ppm, b) Feed concentration; 500 ppm.

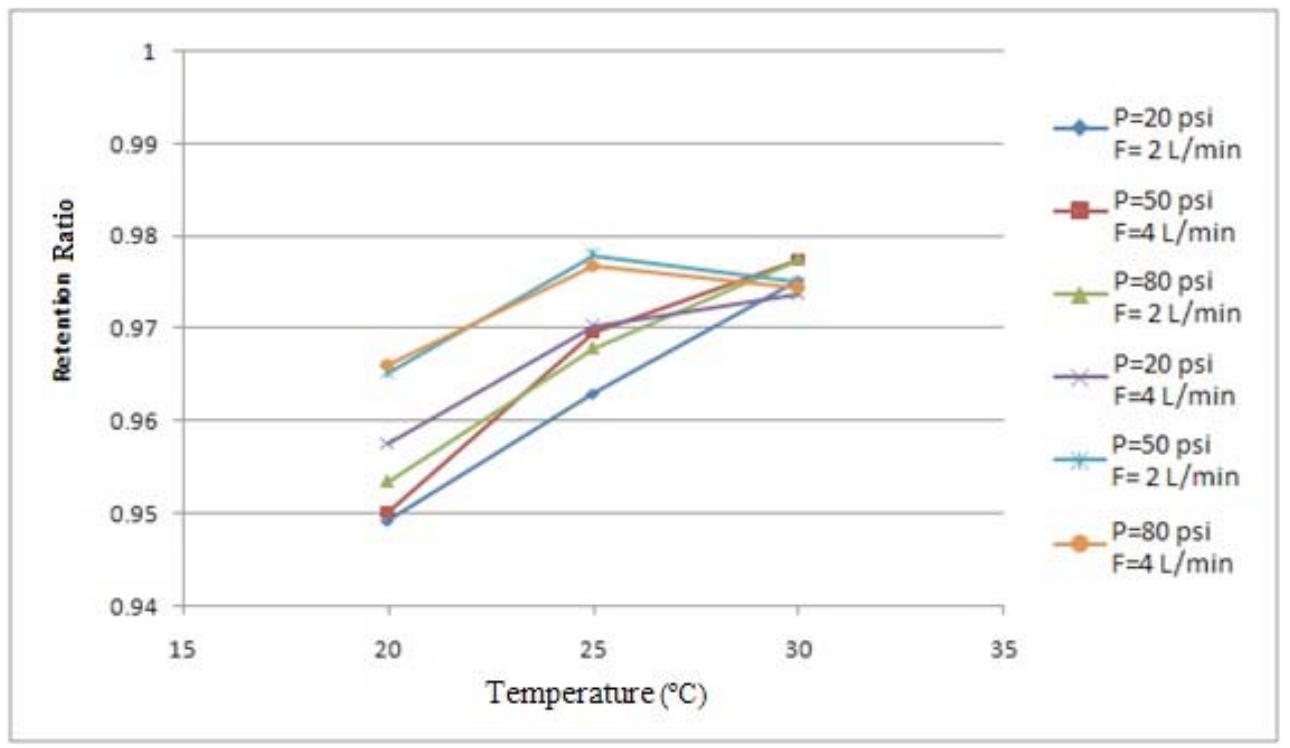

Figure 9: Effect of temperature on sulfate retention (Industrial wastewater). 


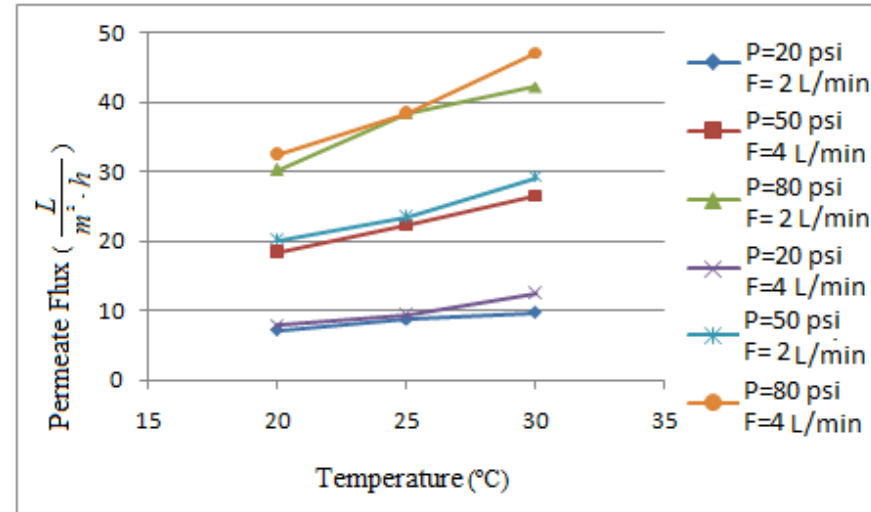

a

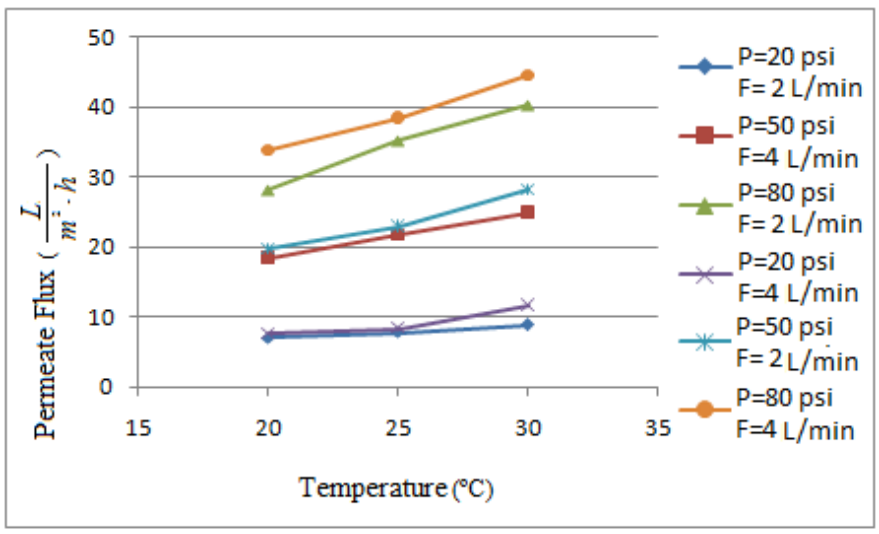

b

Figure 10: Temperature effect on permeate flux (Artificial wastewater); a) Feed concentration; 400 ppm, b) Feed concentration; 500 ppm.

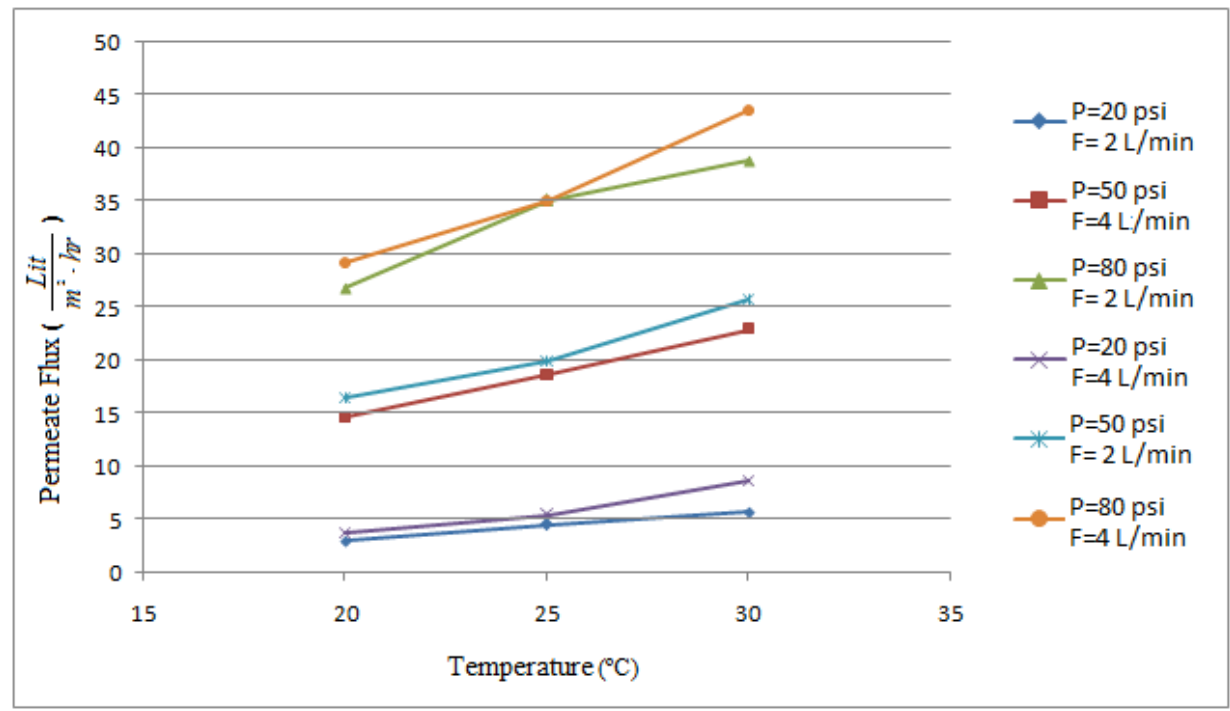

Figure 11: Temperature effect on permeate flux (Industrial wastewater).

\subsection{Effect of Inlet Concentration}

The two inlet concentrations considered in this study were 400 and $500 \mathrm{ppm}$. In this step, other parameters such as operating pressure, temperature, feed volume flow rate and $\mathrm{pH}$ were kept constant. As shown in Figure 12, the effects of inlet concentration on sulfate retention depended depends on feed temperature such that from bottom to top, these effects are different. At low temperature (i.e. $20 \stackrel{\circ}{\circ}$, bottom of the graph), increase in inlet concentration causes the sulfate retention to increase and at high temperature (i.e. $30^{\circ} \mathrm{C}$, top of the graph) the situation is vice versa. In normal temperature (i.e. $25^{\circ} \mathrm{C}$, middle of the graph), no sensitive change was observed in retention. In sum, increase in inlet concentration caused a decrease in sulfate retention. This is due to higher cations concentration, which decreases the negative sites on membrane surface and consequently, anions $\left(\mathrm{SO}_{4}^{2-}\right)$ can pass through the NF membrane. But the sulfate retention is still high because of its big size. It should be noted that in this figure and the following figures (i.e. Figures 13, 14 and 15), there are two points on each line, which have the same conditions except for concentration, and these conditions are shown in separate legends.

Figure 13 illustrates the inlet concentration effect on permeate flux. The results show that at higher inlet concentrations, the flux of permeate stream decreases. Higher solute concentration leads to membrane fouling and consequently, to a higher concentration polarization. This can be mentioned as a reason for flux decreasing which was more sensitive at higher temperature. With regard to industrial wastewater concentration, which is not always at constant level, it 


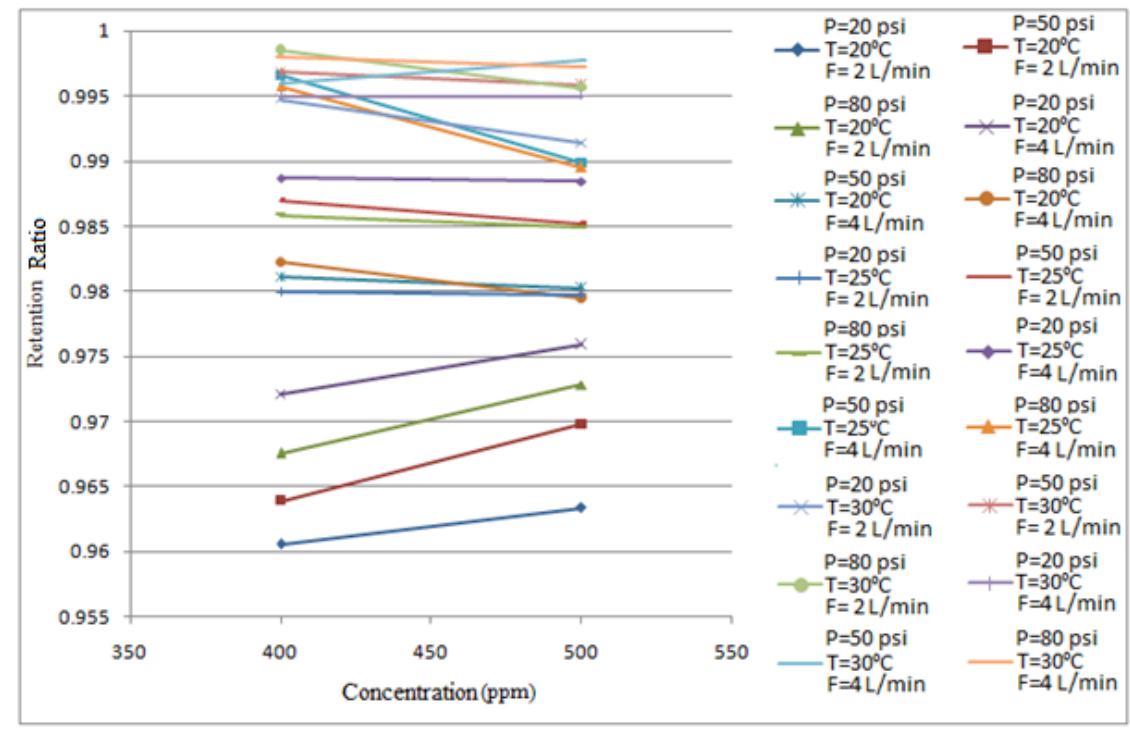

Figure 12: Effect of inlet concentration on sulfate retention (From bottom to top temperature increases).

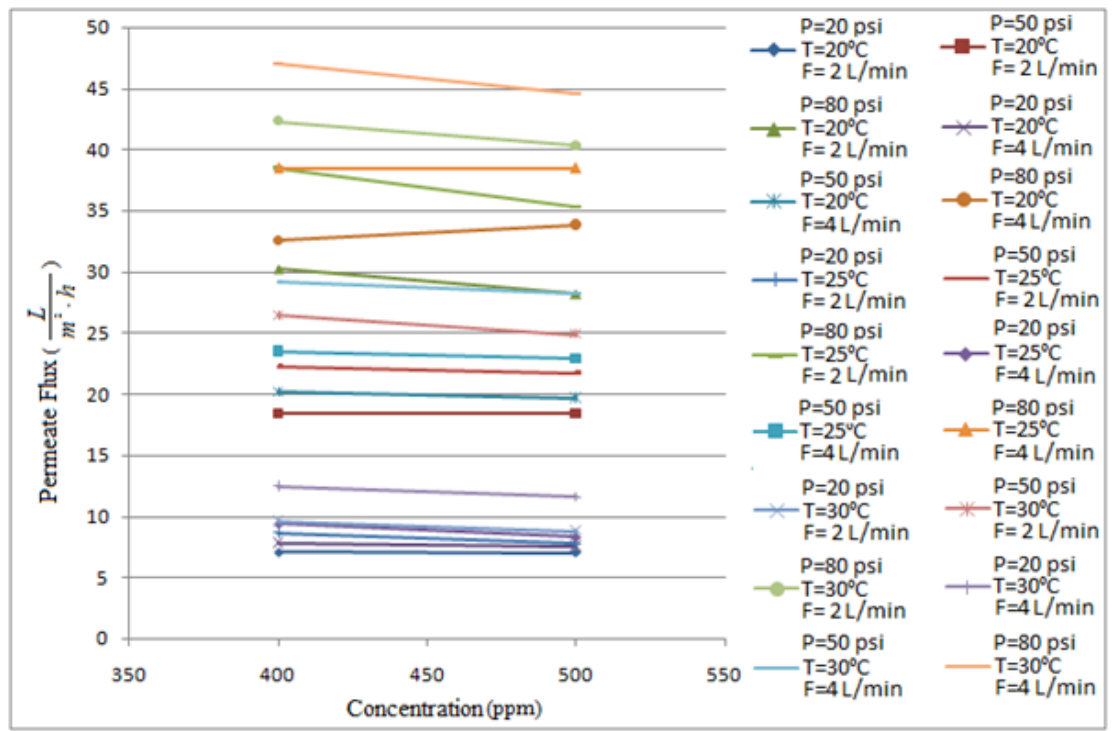

Figure 13: Effect of inlet concentration on permeate flux (From bottom to top temperature increases).

can be concluded that the feed temperature should be kept at the range in which the concentration effects can be neglected.

\subsection{Effect of Feed Volumetric Flow Rate}

The effect of feed volumetric flow rate on the sulfate retention is shown in Figure 14. The results show that sulfate retention increases by increasing flow rate from 2 to $4 \mathrm{~L} / \mathrm{min}$. This is due to the reduction in concentration polarization and less accumulation of cations behind the NF membrane, since the residence time of concentrate before the membrane decreases. Therefore, the membrane preserves its surface charge, which results in higher sulfate retention.
The scale upon the NF membrane, acts as a hindrance against permeation. High ervelocity of the feed over the membrane can remove this scale and also entails thinner boundary layer adjacent to the NF membrane. Hence, the permeate flux will increase (see Figure 15).

\subsection{Optimum Conditions}

To determine the optimum conditions, the process costs and conditions should be surveyed. In this study, the sulfate retention increased by increasing effective pressure upon the membrane. But its rate was not sensitive at higher level, and the operation costs will increase much higher due to higher energy 


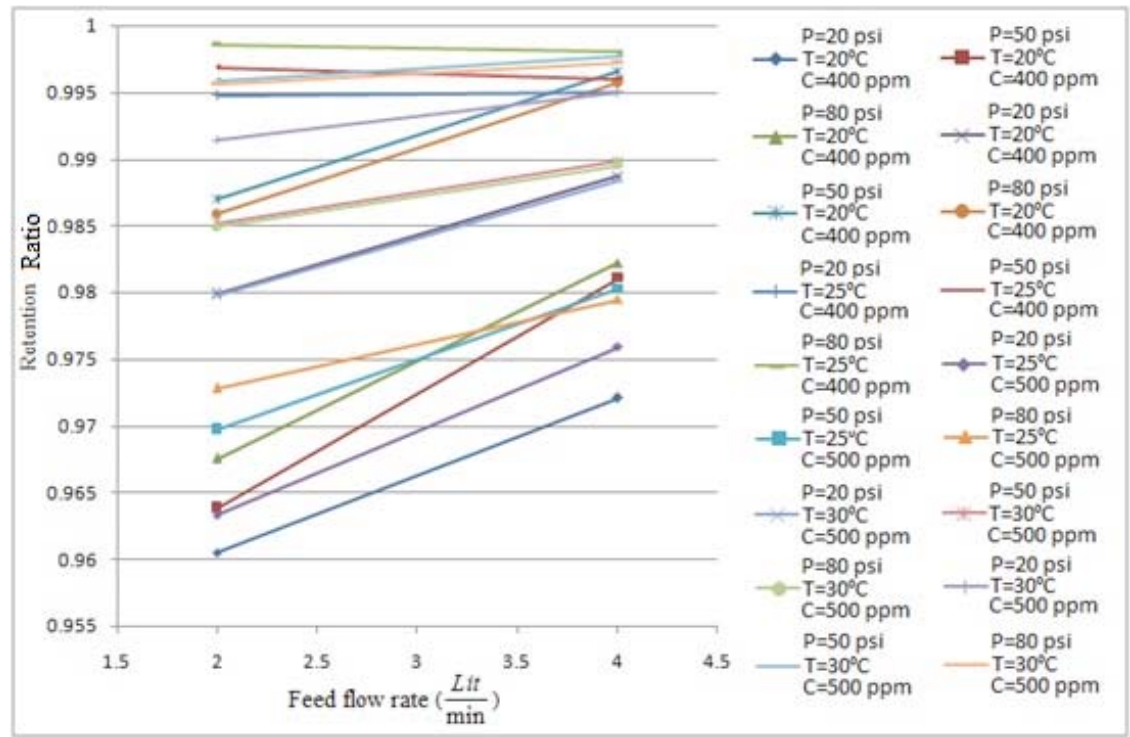

Figure 14: Effect of feed volumetric flow rate on sulfate retention.

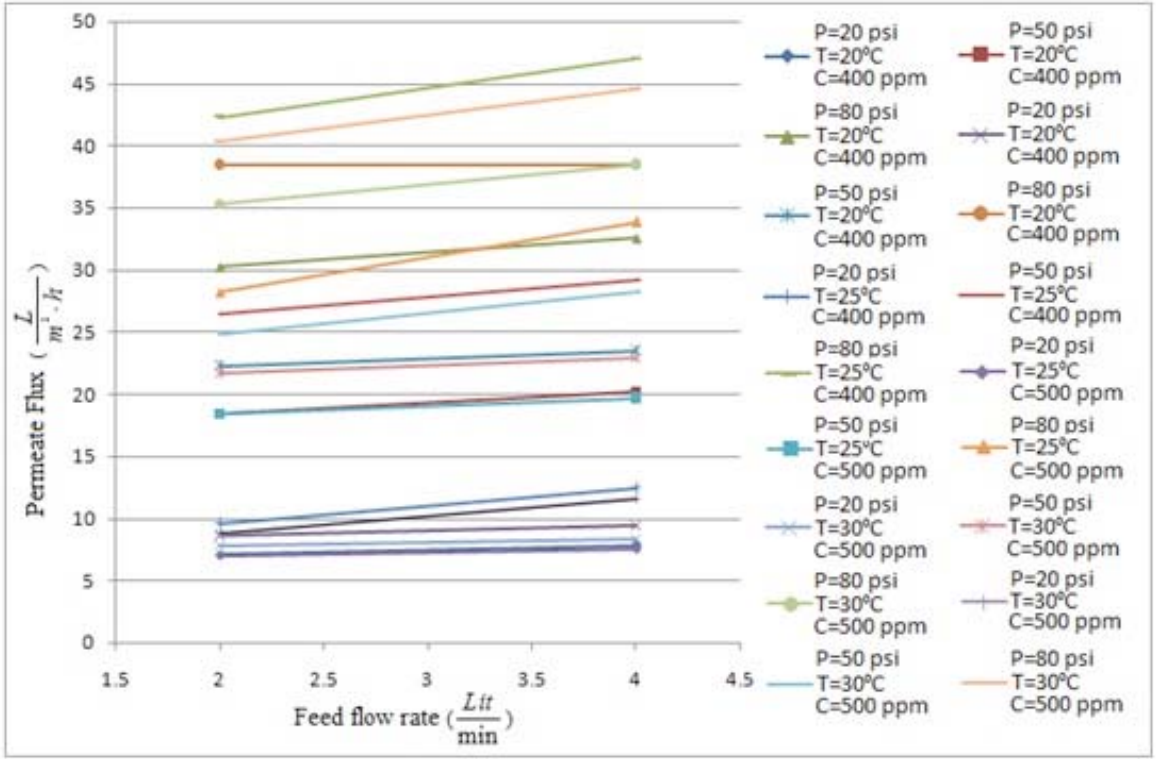

Figure 15: Effect of feed volumetric flow rate on permeate flux.

consumption at higher pressure. According to Figure 4, the optimum pressure was $335 \mathrm{kPa}$, the point that the low variation of sulfate retention against high pressure variation begins.

According to the relation between the effects of temperature and concentration on the sulfate retention, and concentration variation in industrial wastewater, both temperature and concentration should be analyzed simultaneously. For instance, increase in temperature causes a proportionate increase in sulfate retention, but at a high temperature (i.e. $30^{\circ} \mathrm{C}$ ) and a high concentration (i.e. $500 \mathrm{ppm}$ ), the retention rate decreases. Hence, a value of temperature should be selected such that the variation of concentration can be neglected. Consequently, in this study, the temperature of $25^{\circ} \mathrm{C}$ was selected as the optimum one.

Higher inlet volume flow rate leads to higher sulfate retention as well as a higher permeate flux. But the capacity of NF module and of course the endurance of NF membrane should be noticed, which are given in the data sheet. In this study, $4 \mathrm{~L} / \mathrm{min}$ of feed flow rate was selected as the optimum volume flow rate, which is lower than maximum module capacity (i.e. $7.6 \mathrm{~L} / \mathrm{min}$ ). At these optimum conditions the experiments were performed on an industrial wastewater to investigate the effects of other ions which exist in the wastewater. 
Table 3: Analysis of Tehran Oil Refining Company Wastewater on May 21, 2011

\begin{tabular}{|c|c|c|c|}
\hline & Before treatment & After treatment & Removal percentage (\%) \\
\hline \hline Turbidity $(\mathrm{NTU})$ & 156 & 0.3 & 99.80 \\
\hline $\mathrm{SO}_{4}^{2-}(\mathrm{ppm})$ & 437.56 & 11.624 & 97.34 \\
\hline $\mathrm{NH}_{3}(\mathrm{ppm})$ & 3.7 & 0.2 & 34.59 \\
\hline $\mathrm{NO}_{3}^{-}(\mathrm{ppm})$ & 43.3 & 28.5 & 34.18 \\
\hline $\mathrm{TDS}^{\mathrm{a}}(\mathrm{ppm})$ & 1160 & 480 & 58.62 \\
\hline $\mathrm{TSS}^{\mathrm{b}}(\mathrm{ppm})$ & 10 & 2 & 80.00 \\
\hline $\mathrm{Mg}^{2+}(\mathrm{ppm})$ & 32 & 17 & 46.87 \\
\hline $\mathrm{Ca}^{2+}(\mathrm{ppm})$ & 148 & 28 & 81.08 \\
\hline
\end{tabular}

${ }^{\mathrm{a}}$ Total Dissolved Solid.

${ }^{\mathrm{b}}$ Total Suspended Solid.

\subsection{Industrial Wastewaterat Optimum Conditions}

The analysis of important ions in the wastewater of Tehran Oil Refining Company is given in Table 3, before and after treatment. The results showed that sulfate retention was $97.34 \%$ for the industrial wastewater, while this value was $99.66 \%$ for the artificial one and it is still high. Hence, in this study, it can be concluded that the quality of wastewater has no considerable effects on sulfate retention. The difficulty of sulfate passing through the NF membrane can be justified due to its charge (bivalent), large ionic size, and high hydration energy $(1138 \mathrm{~kJ} / \mathrm{mol})$. But for monovalent ions like nitrate $\left(\mathrm{NO}_{3}^{-}\right)$, the ionic quality of the feed affects their retentions. For example, an increase in bivalent ions like sulfate, causes a considerable reduction in the nitrate removal [18]. As one can see in Table 3, nitrate removal percentage is only 34.18. However, this NF membrane can remove at least $60 \%$ of $\mathrm{NO}_{3}^{-}$In order to reach this rate of elimination for $\mathrm{NO}_{3}^{-}$in this study, an extra NF stage is needed, which is placed directly after the first one for sulfate, due to low ionic content of permeate flow at the first stage.

Comparing the flux of permeates for the industrial and artificial wastewaters (i.e. $19.8 \mathrm{~L} / \mathrm{m}^{2}$.hr vs. 23.5 $\mathrm{L} / \mathrm{m}^{2} . \mathrm{hr}$ ) shows a reduction in industrial one. This was due to existence of other ions like nitrate and TDS at high level, which caused some fouling upon the surface of NF membrane and hence, the flux of permeate decreased.

According to Figures 4 to 15 , it can be seen that there are not any major differences in trends of the graphs (i.e. linear, ascending, descending...), between industrial and artificial wastewaters. The solely difference is the numerical value. In other words, for the retention, there were about 1 to $2.35 \%$ reduction and for the flux, this value was about 3.52 to 4.43 $\mathrm{L} / \mathrm{m}^{2}$.hr. These numerical value differences are due to the existence of cations (i.e. $\mathrm{Mg}^{2+}$ and $\mathrm{Ca}^{2+}$ ) and high impurities in the industrial wastewater. The former causes a decrease in surface negative charge of NF membrane and the latter causes some fouling in the NF membrane pores.

\section{CONCLUSIONS}

Although the presence of elevated sulfate anion concentration in industrial effluent is a major environmental concern, it can be remediated with the help of various existing sulfate treatment processes. In this study, the removal of sulfate anion was investigated from artificial and industrial (Tehran Oil Refining Company) wastewaters by nanofiltration process. The results showed that NF90 membrane could efficiently reduce sulfate anions concentration in range of $400-500 \mathrm{ppm}$. The removal of sulfate ions using a nanofiltration process depended on the effective pressure upon the NF membrane, the feed temperature and the inlet volume flow rate. Moreover, the following conclusions were drawn from the results of this study:

1) At higher operating pressure, not more than membrane durability, sulfate concentration in permeates stream and also flux of permeate increased rapidly in comparison with lower pressure.

2) For higher temperature, sulfate retention increased but with higher inlet concentration, the value decreased and there was some relation between temperature and concentration. Also 
there is a limitation due to membrane endurance which should be taken into account.

3) As the volume flow rate was increased up to its limit (i.e. membrane endurance and module capacity), sulfate retention and flux of permeate increased.

Sulfate removals for the artificial and industrial wastewaters were $99.66 \%$ and $97.34 \%$, respectively. The existence of other ions such as $\mathrm{NO}_{3}^{-}$, TDS and so forth in the industrial wastewater led to a reduction in negative sites on membrane surface and a change in electrical balance on both sides of it, and consequently, the retention was lower for industrial wastewater. In this case, the $\mathrm{pH}$ of the solution affected the NF membrane surface charge, as it was not constant in the industrial wastewater. Therefore, detailed studies would be needed to investigate the effect of $\mathrm{pH}$ on sulfate removal by NF process.

\section{ACKNOWLEDGEMENTS}

The support provided by Tehran Oil Refining Company is gratefully acknowledged.

\section{REFERENCES}

[1] Amiri MC. Principles of Water Treatment. sixth ed. Isfahan: Arkan; 2007.

[2] Haghsheno R, Master Thesis, Shahid Bahonar University of Kerman, Kerman, Iran, 2007.

[3] Gurdeep Singh, Yoginder P. Chuggh, Sulfate: Occurrence, Problems and Control Measures, Indian school of mines, special volume 2010; 29-48.

[4] International Network for Acid Prevention (INAP), Treatment of sulfate in mine effluents, Lorax Environmental 2003.

[5] Visser TJK, Modise SJ, Krieg HM, Keizer K. The removal of acid sulfate pollution by nanofiltration. Desalination 2001; 140: 79-86. http://dx.doi.org/10.1016/S0011-9164(01)00356-3

[6] Patrick $H$, Jannie $M$, Jacqueline B. Barium Carbonate process for sulphate and metal removal from mine water, the $9^{\text {th }}$ International Mine Water congress (IMWA 2005).
[7] Košutić K, Novak I, Sipos L, Kunst B. Removal of sulfates and other inorganics from potable water by nanofiltration membranes of characterized porosity. Sep Purif Technol 2004; 37: 177-85.

http://dx.doi.org/10.1016/S1383-5866(03)00206-5

[8] Galiana-Aleixandre MV, Iborra-Clar A, Bes-Piá A, MendozaRoca JA, Cuartas-Uribe B, Ibora-Clar MI. Nanofiltration for sulfate removal and water reuse of the pickling and tanning process in tannery. Desalination 2005; 179: 307-13. http://dx.doi.org/10.1016/j.desal.2004.11.076

[9] Benatti CT, Tavares CRG, Lenzi E. Sulfate removal from waste chemicals by precipitation. J Environ Manag 2009; 90: 504-11.

http://dx.doi.org/10.1016/j.jenvman.2007.12.006

[10] Tait S, Clarke WP, Keller J, Batstone DJ. Removal of sulfate from high-strength wastewater by crystallization. Water Res 2009; 43: 762-72. http://dx.doi.org/10.1016/j.watres.2008.11.008

[11] Haghsheno R, Mohebbi A, Hashemipour H, Sarrafi A. Study of kinetic and fixed bed operation of sulfate anion from industrial wastewater by anion exchange resin. J Hazard Mater 2009; 166: 961-6. http://dx.doi.org/10.1016/j.jhazmat.2008.12.009

[12] Alizadeh A, Najafi FS. Reduction of sulfate concentration from ABS plant's wastewater by anaerobic biological treatment, 1st Iran Petrochemical Conference (IPC), July 2008.

[13] Davis RA, McElhiney JE. The advancement of sulfate removal from seawater in offshore waterflood operation. Corrosion 2002; 7-11.

[14] Madaeni S. Membrane and Membranes Processes.1st ed. Kermanshah: Taghbostan 2002.

[15] Akbari A. Fundamentals of Polymeric Nanomembranes and Nanofiltration Process, 1st ed. Tehran: Pendar Pars 2007.

[16] Dow Chemical Company ("Dow"), FilmTec Membranes, http://www.dowwaterandprocess.com/products/membranes/n f270_2540.htm

[17] Annual Book of ASTM Standard, Water and environmental technology, Vol. 11.01, American Society for Testing and Materials (ASTM) 1991.

[18] Torabian A, Shokuhi Harandi M, Bidhendi G. Nitrate removal from potable water by nanofiltration, $7^{\text {th }}$ International Congress on Civil Engineering (ICCE) 2006.

[19] Paugam L, Taha S, Cabon J, Dorange G. Elimination of nitrate ions in drinking waters by nanofiltration. Desalination 2002; 152: 271-4. http://dx.doi.org/10.1016/S0011-9164(02)01073-1 